\title{
The Use of Magic in Optics in Higher Education
}

\section{Pierre Schott}

Art et Recherche NUMérique, Ecole Supérieure d'Informatique, d'Electronique et d'Automatisme, Paris, France.

Email: schott@esiea.fr, pierrot.schott@laposte.net,arnum@esiea-recherche.eu

Received December 14 ${ }^{\text {th }}, 2009$; revised March 20 ${ }^{\text {th }}, 2010$; accepted April $16^{\text {th }}, 2010$.

\begin{abstract}
Why use Magic for teaching Optics? Magicians know that, once the surprise has worn off, the audience will seek to understand how the trick works. The aim of every teacher is to interest their students, and a magic trick will bring them to ask how? And why? And how can I create one myself? In this article we consider a project I gave in 2006. I summarize the project scopes, the student theoretical studies, their "new" Grand Illusion realization. I conclude by the weak and strong points of this approach... but let's not reveal all the secrets just yet! Whatever the student's professional ambitions, they will be able to see the impact that originality and creativity have when combined with an interest in one's work. The students know how to "perform" a magic trick for their family and friends, a trick that they will be able to explain and so enjoy a certain amount of success. Sharing a mathematical/physical demonstration is not easy and that they do so means that they will have worked on, understood and are capable of explaining this knowledge. Isn't this the aim of all teaching?
\end{abstract}

Keywords: Optics, Ray Tracing, Use Magic for Teaching, Higher Education, Engineer, Educational Method, Grand Illusion, Hodges

\section{Introduction}

From the beginning of time people have feared what they don't understand and sought logical explanations for inexplicable phenomena. To begin with they considered them to be the work of magic, then the work of the gods, then the work of God himself. The church discouraged the spread of the conjurer's art as it preferred not to have rational explanations for what was considered supernatural.

The first magic tricks were performed in the Middle Ages by clowns and/or con-men who would entertain passers-by by getting them to bet on the position of a ball hidden in one of three up-turned goblets, the bet being usually lost. This trick is known nowadays under the name "cups and balls" [1]. The first book considered to be about modern Magic (or should we say "conjuring") was written and printed the $16^{\text {th }}$ Century. It was about Magic with ropes [2]. It wasn't until the end of the 19th Century that the word Magic took on its present-day meaning when the famous magician Houdini, father of modern Magic, made it the art it is today.

Since then a good number of principles have been invented and improved on by magicians and gamblers [3], especially for card tricks with bets. Since the 1980s the secrets that were once passed on from master to apprentice are now universally available through the use of video cassettes and modern communication technology, and Magic has become a Big Business.

The aim of the magician is to hide the principles he uses (using maths, physics, psychology, sleight of hand, etc...) by disguising the trick so that the audience has no way of discovering how it is done thus allowing the Magic to remain.

The teacher can do exactly the opposite: unraveling a Magic trick to high-light the principles used!

\section{The P.E.S Project of ESIEA in the French Higher Education}

We shall see successively the organization of higher education in France, the scope and the objectives of the P.E.S project.

\subsection{The Higher Education in France}

In France, the secondary education is sanctioned by the high school diploma. Ideally the pupils obtain it the age of 18. Then, they have a plethora of possibilities following 3 axes:

1) Some undertake short studies called "professional" in an I.U.T ${ }^{1}$ at the University or in high school with the aim of obtaining a BTS ${ }^{2}$. Both programs lead to a 2-year

${ }^{1}$ IUT: Institut Universitaire de Technologie (in French)

${ }^{2}$ BTS: Brevet de Technicien Supérieur (in French) 
technical degree,

2) Others undertake longer studies. In this case, if they have obtained their high school diploma they can:

- Enrol in university,

- Or enter preparatory courses (classes for entrance into Grandes Ecoles) for 2 years, which will lead them, via national entrance examinations, to enter a 'Grande Ecole' in business or engineering.

The studies take 3 years and once they have their degree in hand, the students find employment easily.

The school in which I work, named E.S.I.E.A, is an engineering school.

\subsection{The Scopes of the P.E.S Project (Project of Engineering Sciences) ${ }^{3}$}

The P.E.S. is a $6^{\text {th }}$ semester project, taking place between February and May (75 homework hours are planned for each student) and students are organized into groups of 4 . Their work is closely followed by a professor. Because the project is to be developed during the student's free time, they also take other courses during this semester.

The subjects can be of three kinds:

1) "Professional" subjects requested directly by the partner companies of the school,

2) "Research" subjects' given by research centers,

3) "Educational" subjects proposed by the school's professors.

The subjects are collected by the school administration, communicated to the students and finally 3 subjects are chosen by each 4-student group. Though an internal process, the students are assigned a subject (most frequently their first request).

\subsection{The P.E.S Educational Objectives}

The main objective is to apply to a project the knowledge acquired during coursework, and if need be, to enrich this knowledge.

A second objective is to raise students' awareness that a project is not reduced to a single academic subject but is in fact a conglomerate of knowledge taught in various courses.

Finally, let us note the importance of project management among these objectives.

An extract of the program, available for consultation on internet [4], is given in Appendix A.

\section{The Assigned P.E.S.}

The contents of a project I assigned to a group of students, the motivations and my expectations are described below.

\subsection{The Proposed Subject in 2005-2006}

3.1.1 Study and Realization of a Grand Illusion

Purpose of the project: to study a new theory through the

${ }^{3}$ P.S.I. Projet des Sciences de l'Ingénieur (in French) design performance of a Grand Illusion.

The magic arts consist of several specialties: close-up, cups and balls, coin tricks, transformists, card trick, and so on... The most mediatized specialty, enjoyed by all kinds of audience, is: the Grand Illusion.

We suggest that you design and perform a Grand Illusion which can be presented several times in the school year to all students and/or to parents and/or to future new students, etc....

\subsubsection{Purpose of the P.E.S.}

The purposes of the P.E.S are thus multiple:

1) To think about the management of confidential information within industry.

2) To read about and understand optics theory.

3) To find documentation about Grand Illusions, and to study it.

4) To write specifications for a NEW Grand Illusion and to construct it.

\subsubsection{Summary}

1) If you want to know the secrets of the greatest magicians, come!

2) If you want to learn a new theory of physics in a fun way, come!

3) Given the vast perspectives of this project, several groups of P.E.S can be trained. So if the work in collaboration between several teams (= services in the company) interests you, come!

ATTENTION: once the secret is known, the illusion loses all its magic... but not its spectacular beauty!

\subsection{My Motivations to Propose Such a Subject}

I chose the topic of magic, a subject which fascinates me, to be virtually certain that the topic would be completely new for the students. So they are in an unknown situation. They will thus have to implement all the necessary means complete the project succeefully.

I also try to arouse the students' curiosity by proposing subject that is more playful than usual.

Following these objectives, I propose a project in optics, while the school in which I work does not teach this subject. I go out very slightly of the project scope because once in a company, the students will have to study or to solve problems that they have never seen during their academic career.

Consequently, the students have to look for, find and understand a new theory of physics.

After all I give them work that is more difficult than that expected by the school. Indeed there is little chance that I will have a student, who is the son or daughter of a magician or who is magician himself.

Finally, I try to change the traditional way of teaching: a downward method (the professor teaches the student) usually used in France, become an ascending method here (it is the student who will have to explain to the 
professor).

The ascending method has the merit of showing whether the posed problem is well understood. As wrote Boileau [5] "what conceives well expresses itself clearly, and the words to say it arrive easily" ${ }^{, 5}$.

\subsection{My Expectations}

I thus expect from my students:

1) That they make perform research on magic and Grand Illusions based on optical illusion,

2) That they perform research in optics:

- Geometrical optics:

Theory of beams for a single lens system.

Equivalent one lens for several lenses system (for example: the astronomical telescope).

- Undulatory optics (several Grand Illusions are based upon)

Study light interferences due to the electromagnetism taught in the $3^{\text {rd }}$ and $4^{\text {th }}$ semester (for example: Young's holes)

An introductory study of the phenomenon of diffraction.

3) That every group-member knows (by heart) the theories and that each of them can explain these theories to the professor.

4) That the realization is interesting about both angles: magic and optics.

The Grand Illusion will have to be original and creative and, it must solve the given problem correctly. Finally its presentation during the diva must be well organized and as magic as possible.

\subsection{The Group Composition}

Two groups chose this project. Each met one of the two objectives that I had set but neither managed to meet both objectives. Is this due to the subject or to the composition of the groups?

The first group consisted exclusively of students who were members of the Student Union ${ }^{6}$.

The second consisted of "above average" students according to the standards of evaluation used in France.

\section{Realization of Group Number 1}

\subsection{Theory of Optics}

In a few pages, the students gave only the theory of geometrical optics onto the forming of images (convergent and divergent simple lenses, mirrors, association of two simple lenses); this part of the work was relatively complete. But only one of them knew only approximately this theory (what we noticed during the oral

\footnotetext{
4“ce qui se conçoit bien s'énonce clairement, et les mots pour le dire arrivent aisément"

${ }^{5}$ Pierre Schott's translation

"B.D.E" in French as Bureau Des Etudiants
}

presentation).

Finally, they did no work on interferences and the notion of diffraction-in spite of my repeated requests during follow-up!

\subsection{Summary of Grand Illusion in Literature}

I think that among all Grand Illusions they found, the students have decided to explain in their report only one-with which a magician is able to make disappear an object, a human being or a part of it...-which is the base of their own Grand Illusion.

In their report, they wrote:

"The first idea, which we had, consists in being able to hide something or somebody behind a mirror ${ }^{7}$. The principle is simple. Our set up consists of a cube opened on the front (Figure 1).

Then we place a rectangular mirror in the same cube (Figure 2).

The right wall (BCGF) is reflected by the plane mirror when $\mathrm{we}^{8}$ are in front of the cube. So each person situated in front of the stage sees the background of the cube in the left side, and on the contrary, in the right side, the background is hidden by the mirror and the spectators see the reflected image of right side by the mirror (Figure 3). A bar placed on the (IJ) edge from top to bottom is enough to hide the mirror edge.

In small-scale cube (approximately 50 centimeters cube edge), we can hide small object or even our hand if we drill a trapdoor on the top ${ }^{9}$ to be able to reach inside

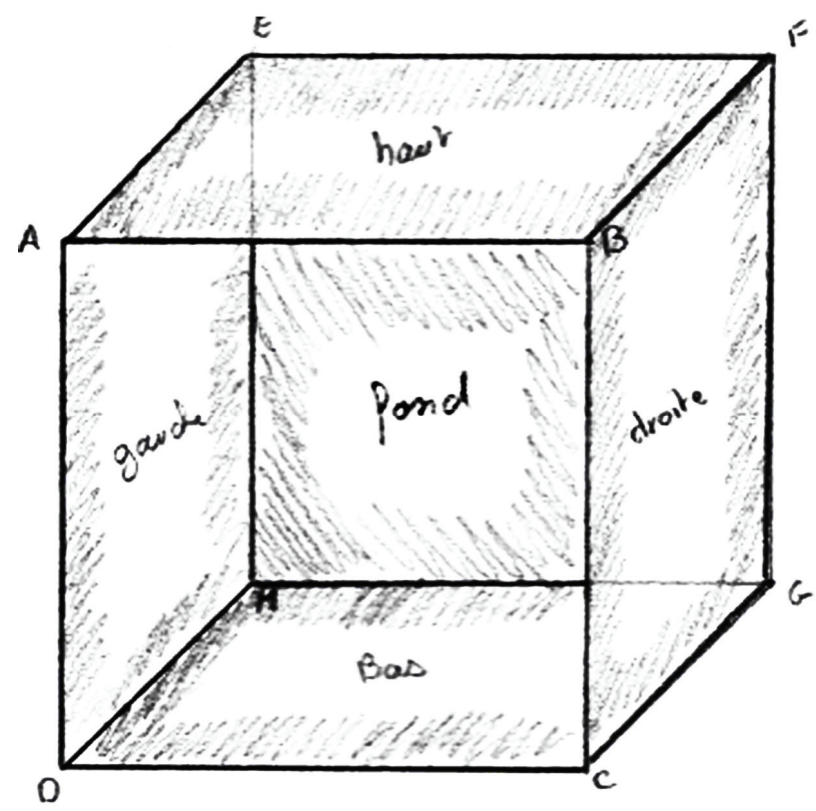

Figure 1. Display of the Grand Illusion "Disappearance": simple cube

\footnotetext{
${ }^{7}$ Magician note: it would be greater to write "thanks a mirror"

${ }^{8} \mathrm{We}=$ the spectators

${ }^{9}$ Lecturer note: better read bottom!
} 


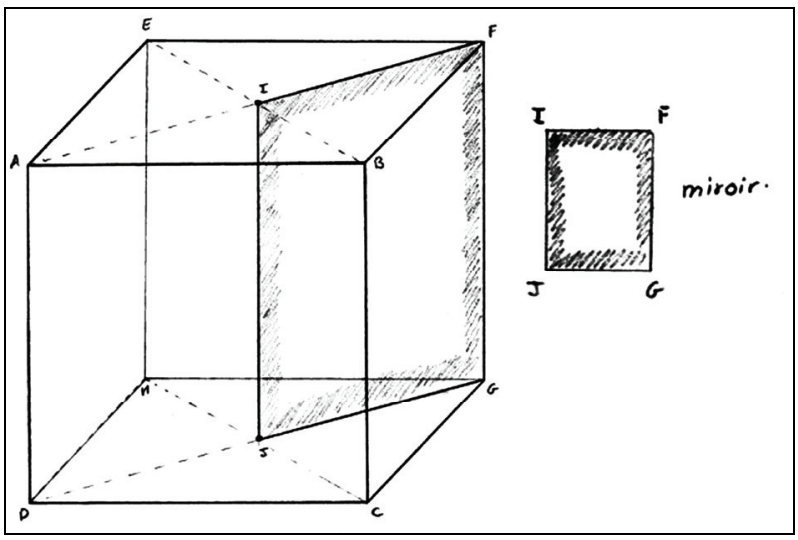

Figure 2. Display of the Grand Illusion "Disappearance": simple cube with the mirror

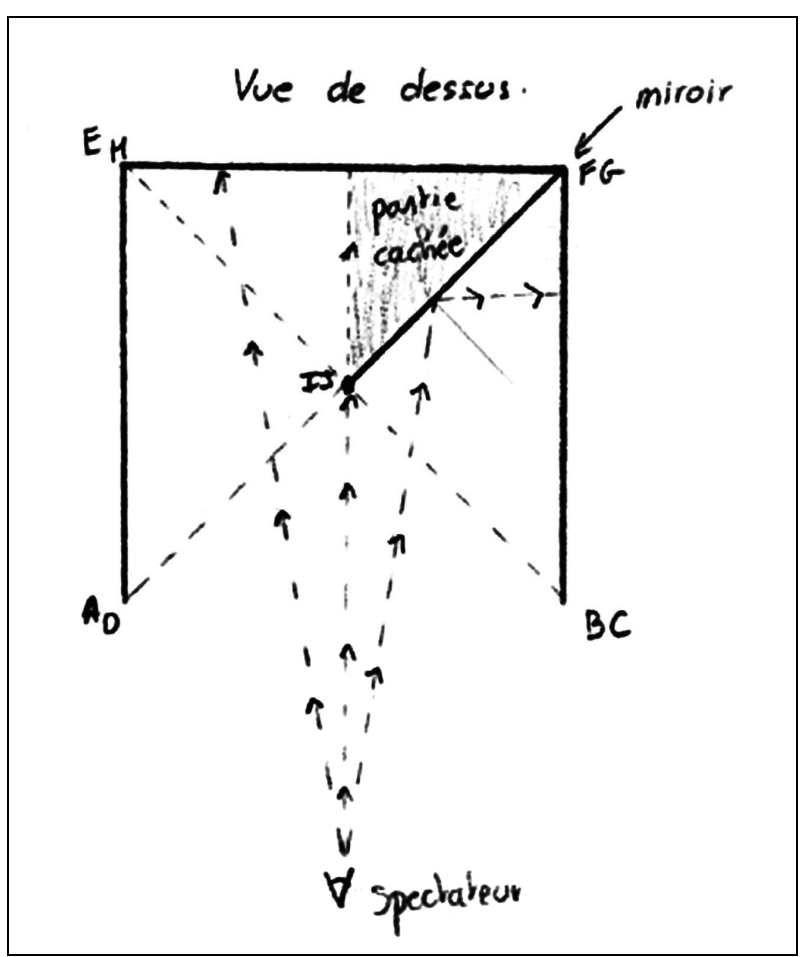

Figure 3. Display of the Grand Illusion "Disappearance": multiple reflections beams

our stage. In large-scale cube (approximately 2 meters cube edge) we can remove persons but we do not envisage this eventuality in the first place due to the budget but also for handiness reasons on the stage. Even if this system is practicable, we did not intend to create it because a spectator situated too close to the stage could discover the secret."

It is a very classic Grand Illusion which is a direct application of the image construction thanks to the geometrical optical theory. I am very satisfied that the students found this idea and even more that they do not content themselves with it. Indeed their project would lack of personal creativity.

\subsection{Their Own "New" Grand Illusion}

"The second idea we had is to create an unlimited tunnel thanks to two opposite mirrors. The principle is slightly more complicated but can be more interesting. Our tunnel is also based on a cube (Figure 4).

This time, all the faces are closed. For the sides, the bottom and the top of the cube (AEGD, BFHC, CDGH, ABFE), we used some wood or some cardboard. On the background (EFHG), we placed a mirror and on the front side $(\mathrm{ABCD})$ we placed a two-way mirror allowing the vision in the one way from outside to inside (direction $\mathrm{AE}$ for example).

It is necessary, for well working, that the inside of the cube is much more brilliant than the outside. Indeed, the two-way mirror although if it makes dark all around the observer and it is luminous inside the cube. The simplest solution to remedy for this problem was to place a light source in our cube for becoming in darkness. To become the outside dark, it is necessary switch off any light sources.

The principle of such a construction is that the spectator looks through the two-way mirror the only thing which he can see is the reflection of a mirror on the other to infinity. Our cube gives the illusion to be an unlimited tunnel (Figure 5)." [6]

The technical drawing of this Grand Illusion is presented to the Figure 7, in Appendix B.

It is necessary to add that this idea is very old and was realized many times and not always in a "magic" way. For me, its most beautiful realization is the gallery of

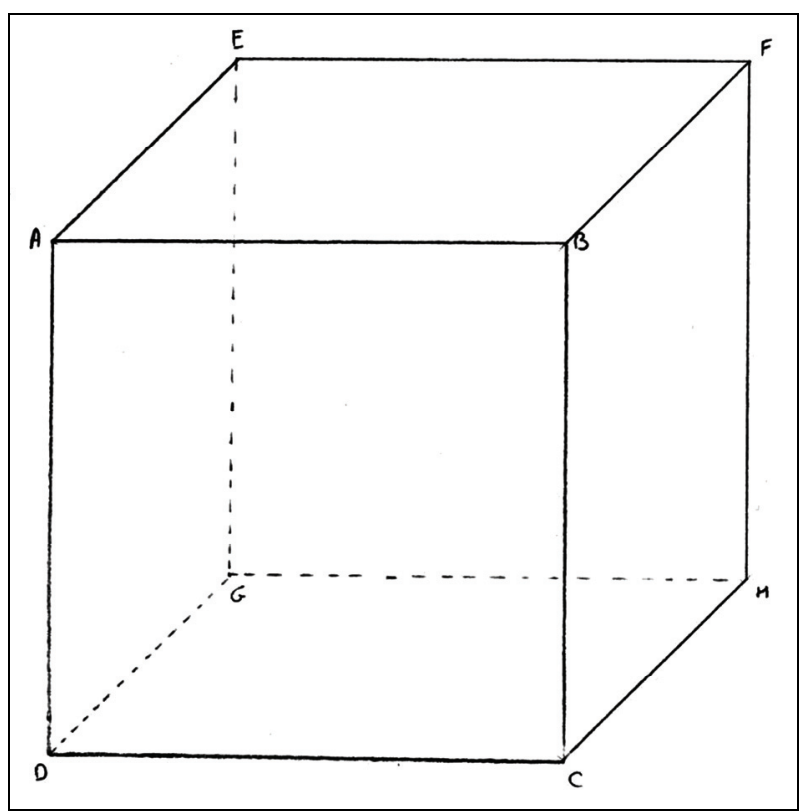

Figure 4. Display of the Grand Illusion "unlimited Tunnel": simple cube 


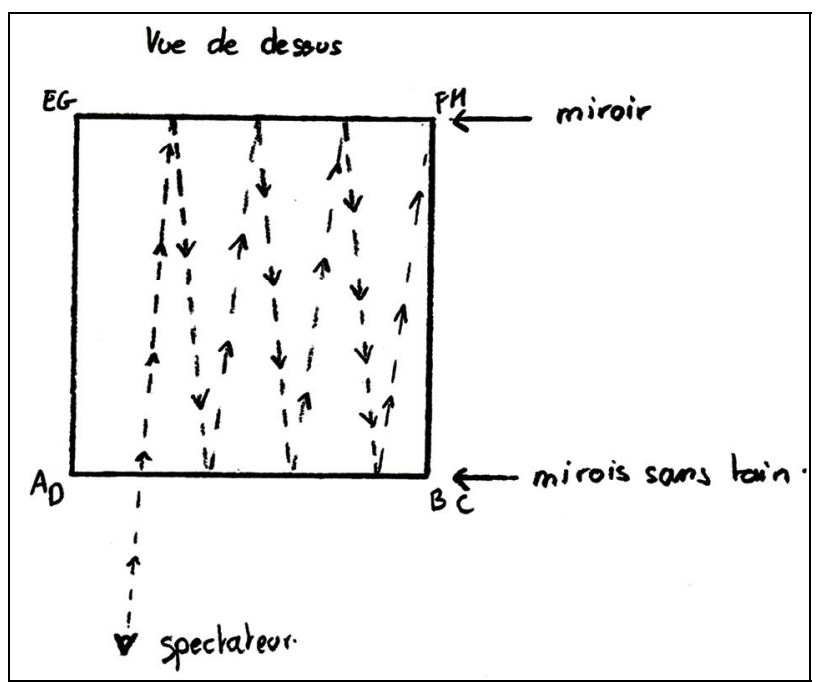

Figure 5. Display of the Grand Illusion "unlimited Tunnel": explanation of the beams ways

mirrors, in the castle of Versailles wanted, by Louis XIV. What recovers of the originality of their project is to use a two-way mirror what allows to have really a magic trick which I am now going to describe below and what was presented to me during their oral presentation.

A student (finally I shall have to say the magician) takes a box and show it to the public who can test the rigidity of all the faces. He is standing and puts this box on his belly. The magician switches on the inside of the box and the spectators see the box lengthening towards the back through the magician stomach! The magician switches off the box and show it to the public (it takes back its initial size!). He taps too his abdominal muscles to show that they are very hard and that there is not a hole anymore!

\section{Realization of the Group Number 2}

\subsection{Theory of the Optics}

In few pages, the students gave all the theory of the geometrical optics onto the images construction (for convergent and divergent one lens system, mirrors, association of two lenses) and also simple applications of the undulatory optics by the study of the holes of Young.

\subsection{The Grand Illusion}

The idea we chose to realize a mini illusion is the idea of one of our P.S.E members: Charles Weisgerber. He saw it in the exhibition "La Seine des photographes" in the Conciergerie in Paris. Indeed, the concept of mirrors "W" was realized with Seine's photos and impressed us at the first sight by its realism of three dimensions vision. We have chosen to conceive an appropriate model for our workgroup. That was going to help us to understand the physical phenomena which hide behind this illusion.
We naturally construct it with our personal touch to answer to our subject. We did not consequently invent anything but we understood an idea to reshape it for our P.E.S by bringing it the necessary modifications [7].

The example was put in the report and was explained during their oral presentation, is presented in Figure 6.

For me, there is no creativity enough and their realization is not at all magic! We find right now the optical illusion... and not a Grand Illusion.

\section{Synthesis, Conclusions, Going Further and Prospects}

Before asking the following question "Is it opportune to develop this type of teaching?", let me make a synthesis of students' work, then a conclusion in relation to my expectations and finally suggest ways to go further.

\subsection{Synthesis}

Let us sum up my expectations in Table 1:

[Rq 1]: The "grand" illusion is only a mirage!

[Rq 2]: The astronomical telescope was not dealt with.

[Rq 3]: This group invented a new Grand Illusion (to my knowledge), and presented it with an elaborated artistic sense: which gave a perfect answer to the magic problem.

[Rq 4]: This group learnt nothing in terms of theory except for one member.

[Rq 5]: The link between theory and practice was made for the oral presentation but regrettably not in their report.

\subsection{Conclusions}

Let us look at the work supplied by both groups in Table 2:

If the work of group 1 and group 2 could be brought together, the report would completely reach my expectations and objectives. That is why I can think that this method is efficient and practicable.

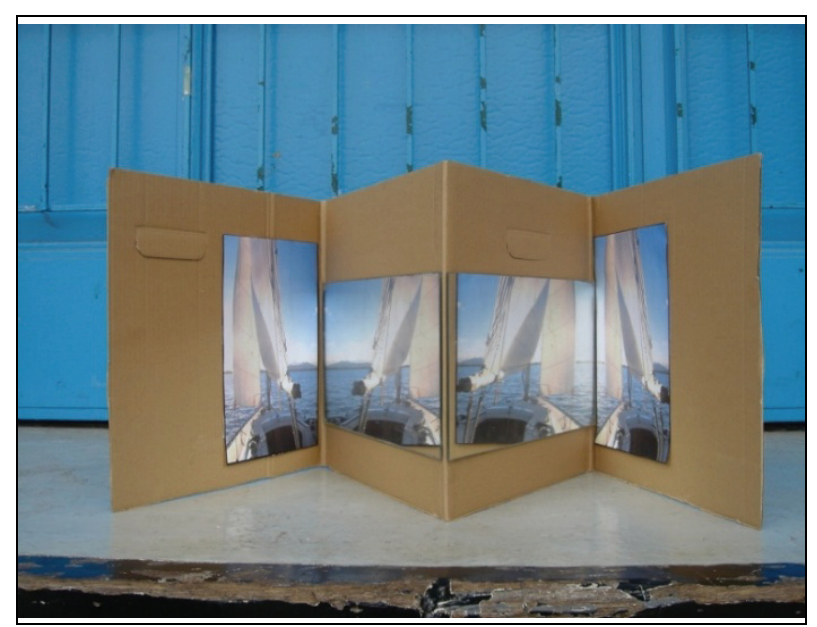

Figure 6. Realization of the "Grand Illusion" by the second group 
Table 1. Synthesis of student work

\begin{tabular}{|c|c|c|c|}
\hline & Expected objectives & Group 1 & Group 2 \\
\hline & Magic documentation & Good & $\begin{array}{l}\text { Average } \\
{[\text { Rq 1] }}\end{array}$ \\
\hline \multirow{2}{*}{$\begin{array}{l}\text { Geometrical } \\
\text { optics }\end{array}$} & $\begin{array}{l}\text { Theory of beams for a } \\
\text { single lens system }\end{array}$ & Very Good & Very Good \\
\hline & $\begin{array}{l}\text { Equivalent one lens system } \\
\text { for several lenses system }\end{array}$ & $\begin{array}{l}\text { Good } \\
{[\operatorname{Rq} 2]}\end{array}$ & $\begin{array}{l}\text { Good } \\
{[\operatorname{Rq} 2]}\end{array}$ \\
\hline \multirow[t]{4}{*}{$\begin{array}{l}\text { Undulatory } \\
\text { optics }\end{array}$} & $\begin{array}{l}\text { Approach the lightly inter- } \\
\text { ferences thanks to the } \\
\text { electromagnetism given in } \\
\text { the 3rd and 4th semester }\end{array}$ & Not done & Very good \\
\hline & $\begin{array}{l}\text { Approach slightly the } \\
\text { diffraction phenomenon }\end{array}$ & Not done & Quite good \\
\hline & $\begin{array}{l}\text { Conception and realization } \\
\text { of their new Grand Illusion }\end{array}$ & $\begin{array}{c}\text { Excellent } \\
\text { [Rq 3] }\end{array}$ & $\begin{array}{l}\text { Nothing } \\
\text { Magic }\end{array}$ \\
\hline & $\begin{array}{l}\text { Explanation of the theo- } \\
\text { retical points during the } \\
\text { oral presentation }\end{array}$ & $\begin{array}{l}\text { None } \\
{[\text { Rq 4] }}\end{array}$ & $\begin{array}{l}\text { Good - very } \\
\text { good [Rq 5] }\end{array}$ \\
\hline
\end{tabular}

Table 2. Synthesis of students work by macro objectives

\begin{tabular}{cccc}
\hline Objective N & Asking Objectives & Group 1 & Group 2 \\
\hline 1 & $\begin{array}{l}\text { discover a new (for students) } \\
\text { existing theory and perfectly } \\
\text { know it. }\end{array}$ & No & Yes \\
2 & $\begin{array}{c}\text { Implementation of a project in a } \\
\text { very different context from theirs }\end{array}$ & Yes & No \\
\hline
\end{tabular}

But each group was interested in only a part of the whole project subject.

We can thus conclude that if each group had been less homogeneous, it would have been able to achieve fully the objectives and the expectations. This leads to a more directive role than I imagined on the part of the teacher regarding the composition of the groups.

These groups are formed spontaneously according to the affinities and the common points of the individuals. It is this homogeneity which will allow them to work together and to achieve successfully the given project.

\subsection{Going Further}

So I'm wondering if, half-way through, I should not have:

1) chosen one of the two illusions and imposed it on each group?

2) chosen one of the two illusions and imposed in on both groups to realize this project successfully by merging both groups into one?

3) mixed the ideas of both groups' proposed illusions in order to invent a new one and impose it on both groups (or both groups united together)?

4) mixed both groups by breaking their homogeneity but by obliging the students to use the talents of each?

None of these solutions seemed interesting to me be- cause they break an essential aspect of the project: by choosing a single illusion, I depreciate the other one in the student's eyes, by mixing the groups I break their homogeneity and risk demobilizing them. It is therefore up to the teacher to show himself more directive when monitoring the project.

The project of group 1 shows that strangely, the written work is focused on the area of magic: the students left aside the physical problem to concentrate on the elaboration and the realization of the illusion. This group probably thought that, if the illusion was achieved, the project would be too and the professor would be clement with them.

The project of group 2 shows the opposite. By not being interested in the magic, the students doubtless thought that if the theoretical aspect was well learnt and displayed, the aim would be achieved.

The professor will thus have to remedy it by being inflexible: the students will have to reach the final aim and all the objectives and the sub-objectives must be achieved too. The teacher must be careful that the ludic aspect remains rewarding but without it predominating the given theoretical work.

\subsection{Prospects}

I continued to propose these kinds of subjects and by a more formal follow-up, the results improved. One group even suggested to me a different (magic) subject which I reformatted to fit the P.E.S imperatives.

What leads me to think about adapting this to the whole physics teaching is to use illusions (or magic) as a method of investigation to lead students to understand the principles of Physics and to come to love this subject.

\section{Acknowledgements}

This paper could not have been written without the encouragements of Bernard Schott, my father, the invaluable help of Anne Serrie, my mother, Claire Leroux, the head of ARNUM, Susan Loubet, Jane Jacquemet and Peter Wilson, who corrected the English.

\section{REFERENCES}

[1] H. Mayol, "La Magie des cordes Maestro," Human Body Model Production, 2000.

[2] M. Ammar, "The Complete Cups \& Balls," L \& L Publishing, 1998.

[3] S. W. Erdnase, "The Expert at the Card Table," Chicago, 1902.

[4] https://bizet.esiea-ouest.fr/bases/esiea/pedagogie/t

[5] N. Boileau, "La scolastique," Souchay, Paris, 1740.

[6] G. Levental, P. Ly, B. Spagnol, C. Guichard and A. Azzopard, "Etude et réalisation d'une grande illusion," Mémoire de P.S.I, ESIEA, 2006.

[7] A. Boue, J. Elbaz, A. Friedlander, N. Tamburini and C. Weisberger, "Etude et réalisation d'une grande illusion," Mémoire de P.S.I, ESIEA, 2006. 


\section{Appendix A}

\section{A.1 The Objectives}

The Projects of Engineering Sciences (P.E.S), workshops proposed to the $6^{\text {th }}$ semester students, group activities of project type which take place throughout the winter semester (from 01/30/2006 till 05/31/2006).

Their main objective is the study of concrete applications in companies, technico-scientific matters leading to a realization or an experiment. The aspects of human formation and of project management will have to be there approached.

They also allow developing the work in a group, the communication techniques as well as the collaborative work.

\section{A.2 The Activities}

The students, 3 to 5 students per group, are accompanied by a teacher.

1) They develop their project.

2) They make an intermediate report.

3) They draft a final report.

4) They speak during an oral presentation.

\section{A.3 The Subjects}

The subjects are proposed by teachers of various matters: electronic systems, physics, signal and Fourrier-analysis, scientific calculation, human formation, communication, ...

The proposed subjects list will be available on the office of the assistant educational and posted at the latest on December $14^{\text {th }}, 2005$.

Every domain has a number of limited subjects.

A students group can propose a subject: they have to find a teacher who wants to follow this group with their subject. Then the group must contact the educational assistant which takes care to register the project.

\section{A.4 The Teacher}

He accompanies the students group in their work and is in charge of the evaluation.

He assures three major meetings:

1) In the beginning of activity, he advises and directs the students group.

2) During the intermediate balance report, he reorienttates possibly the group and estimates the presented work.

3) At the end of activity, during the oral presentation.

\section{Appendix B: Technical Drawing of the Grand Illusion "Unlimited Tunnel"}

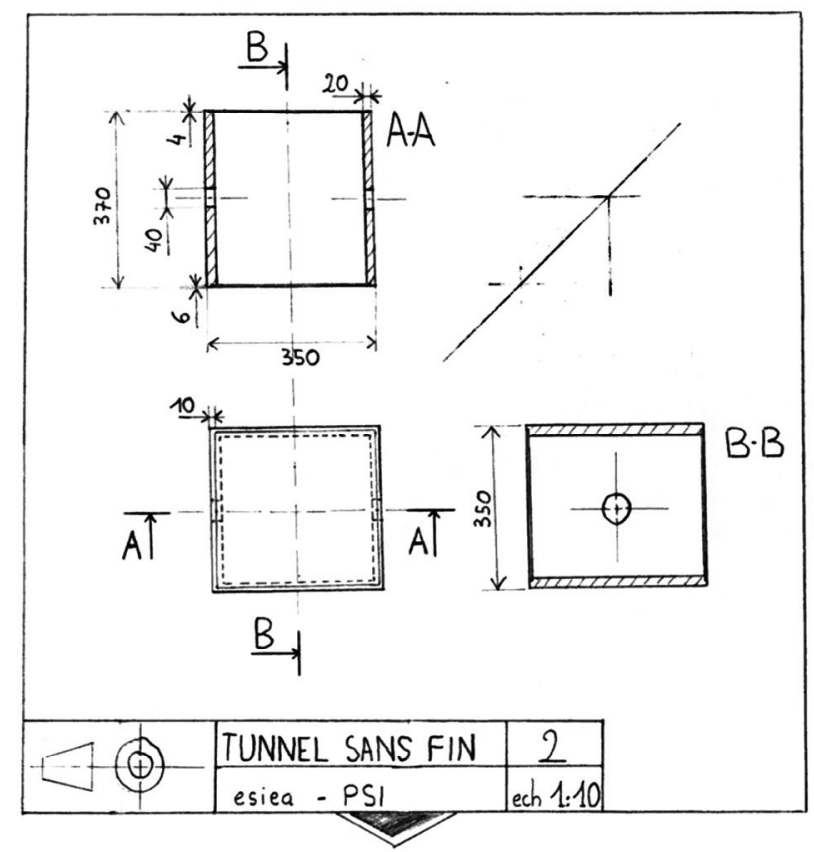

Figure 7. Display of the 'Grand Illusion' unlimited: unlimited drawing 